\title{
CONVECTION COEFFICIENT ESTIMATION OF STILL AIR USING AN INFRARED THERMOMETER AND CURVE- FITTING
}

\author{
Tuba Yenera (iD, Şuayb Çağrı Yener ${ }^{\text {* }}$ (D), Reşat Mutluc \\ ${ }^{a}$ Department of Metallurgy and Materials Engineering, Sakarya University, 54187 Esentepe Campus, \\ Sakarya, Turkey, \\ tcerezci@sakarya.edu.tr \\ ${ }^{* b}$ Department of Electric and Electronic Engineering, Sakarya University, 54187 Esentepe Campus, \\ Sakarya, Turkey (*corresponding author) \\ syener@sakarya.edu.tr \\ ${ }^{c}$ Department of Electronics and Telecommunication Engineering, Namık Kemal University,59860 \\ Çorlu, Tekirdă̆, Turkey \\ rmutlu@nku.edu.tr
}

\begin{abstract}
The convection coefficient is an important thermal property. In this study, using an infrared thermometer, the convection coefficient of still air is estimated. First, the sample is heated in a sintering oven, then placed on a wood table for obtaining an almost adiabatic boundary, finally its temperature is recorded with respect to time using an infrared thermometer. The data is curve-fitted to find the sample temperature as a function of time. Using the sample's physical dimensions, the specific heat capacity and the mass of the sample, the convection coefficient of still air is estimated.
\end{abstract}

Keywords: Thermal analysis, convection coefficient measurement, thermal models, curve-fitting

\section{Introduction}

It is important to model heat transfer dynamics of the systems [1], [2]. Newton's law of cooling is used to describe natural cooling of objects [2], [3]. The convection constant or the heat transfer coefficient $\left(h_{c}\right)$, is used in thermodynamics to calculate the heat transfer typically occurring by convection. The coefficient is very important parameter in science and engineering [1], [2], [4]-[10]. Dynamic analysis of some thermal systems cannot be done without this 
parameter and numerical studies of such systems also require using it. The following studies given in [5]-[22] are to be summarized to show its importance as the follows.

In [5], numerical investigation of unsteady natural convection problem in vertical open ended, and porous cylinder which has been done to simulate the transient heat mass convection in the grain storage in silos. In [6], an approximate solution for the application of the Kirchhoff transform to thermal spreading problems with convection in the sink plane is developed and the technique is shown to be accurate to within $1 \%$ for relevant problems in device-level thermal analysis. In [7], an experimental study is reported on the laminar forced convection of $\mathrm{Al}_{2} \mathrm{O}_{3}-$ water and $\mathrm{Al}_{2} \mathrm{O}_{3}$-polyalphaolefin nanofluids through a circular minichannel and it is found that Although nanofluids enhance convective heat transfer, the results show that their thermal effectiveness is adversely offset by the combined effects of increased viscosity and lower specific heat. The study given in [8] has presented a new more accurate formulation for determining the surface temperature of a magnetic core using the following two characteristic parameters: the height of the core and the average convective heat flux dissipated from the side surface and both natural convection and radiation are accounted for, using finite-element-based simulations without using a constant heat transfer coefficient. This experimental study in [9] has investigated heat-transfer physics of forced convection in a reciprocating square duct fitted with $45^{\circ}$ crossed ribs on two opposite walls.

In [10], the effects of the multigrid technique on the accuracy and efficiency in describing convective heat transfer in closed and open cavities with and without liquid-solid phase changes of Newtonian and shear-thinning non-Newtonian fluids are analyzed. In [11], the results of a numerical study of the melting and natural convection in a rectangular enclosure heated with three discrete protruding electronic components which are the heat sources mounted on a conducting vertical plate are given. In [12], the natural convection in an inclined porous rectangular cavity is examined numerically. In [13], the influence of pulsating flow on convection heat transfer in corrugated tube is inspected through numerical simulation at case of different pulsating amplitude and different. pulsating frequency. A CFD study of natural convection heat transfer from an enclosed assembly of vertical cylinders is given in [14] and the heat transfer coefficient is calculated. A full grid interval collocation method (FGICM) and a sparse grid interval collocation method (SGICM) is proposed to solve the uncertain heat convection-diffusion problem with interval input parameters in material properties, applied loads and boundary conditions in [15].

The effect of convective heat transport in modelling the early evolution of conduits in limestone aquifers using a flow-heat-solute coupled karst evolution model is quantified in [16]. The temperature field within evaporating ethanol droplets is investigated, relying on the two-color laser induced fluorescence (LIF) measurement technique and on a Direct Numerical Simulation which takes into account key aspects of the droplet heating and evaporation such as the nonuniform and transient stress, and the mass and heat transfer coefficients at the droplet surface in [17]. The effect of heat convection on drying of porous semi-infinite space with a heat flux condition on the fixed face $x=0$ is examined in [19]. The numerical study in [20] investigates the convective heat transfer and flow fluid inside a horizontal circular tube in the fullydeveloped laminar flow regime under the constant wall temperature boundary condition to get the steady temperature distribution in the fluid. In [21], a heat convection length, $\Delta \mathrm{s}$, which can greatly simplify the analysis, yet allow the convection characteristics to be retained is proposed instead of having to simultaneously solve governing equations for conservations of mass, momentum, and energy to find the heat transfer coefficient, $h$, to make the calculations easier for contemporary undergraduate students. 
In [17], A process control method for the electric current-activated/assisted sintering system based on the container-consumed power and temperature estimation is developed by showing that the radiated and convection heat transfer can be ignored during the heating of the system. The parameter can also be used to model biological systems [18]. The various studies given in [5]-[22] requires the heat transfer coefficient and shows how important the parameter is in science and engineering. That's why it is of importance to calculate it.

A simple way to calculate $h$ is to define it through the classical formula for convection obtained by Newton's law of cooling [3]. Both the ambient and the sample temperature are important to estimate $h_{c}$. Thermal energy of a uniform object is calculated using its mass and its specific heat capacity which is one of the characteristic properties of a material [2]. Such a properties are listed in material handbooks and measured for new materials commonly [23]. It is important to measure the thermal properties of the new materials using cheap and accurate methods. Infrared thermography can also be used to determine Air Side Convective Heat Transfer Coefficient [24]-[27].

Measurement of the convective heat-transfer coefficient is made using the thermal time constant in [25]. In this study, an infrared thermometer is used to measure and record the sample temperature with respect to time and then a least-square curve-fitting method is used to find the ambient temperature instead of using an iterative method required by setting an initial value of the ambient temperature. Temperatures of the cylindrical samples are measured used using an infrared thermometer. A sintering oven is used to heat up a sample. The sample is then taken out and placed on a wood for having thermal insulation and obtaining an almost adiabatic boundary. Then, the heated sample temperature is measured with an infrared meter. From the recorded data, the thermal time constant is obtained. Then, using the physical dimensions and its measured mass, its specific heat capacity, the convection coefficient of still-air is estimated using both of the samples.

The paper is arranged as the follows. After this introduction, in the second section, the measurement system used in experiments is explained and the samples are introduced. In the third section, the heat transfer model of the system is given. In the fourth section, the experimental results are given, the results are curve-fitted using least squares method, and the convection coefficient of still-air using the samples are estimated. The paper is concluded with the last section.

\section{Materials and method}

The samples used in this study and their parameters are shown in Figure 1 and their dimensions are given in Table 1. The sample is placed on a wood table for thermal isolation during cooling. A 8000 Watt sintering oven is used to heat up the samples. After heating the sample in the oven during considerable amount time, the sample is taken out and put on the table. An infrared thermometer is placed about $70 \mathrm{~cm}$ away from the sample put on the table and the experimental setup system is depicted in Figure 2. The sample temperature is recorded with respect to time during the cooling process.

Table 1. Physical Dimensions of the Samples.

\begin{tabular}{|l|l|l|l|}
\hline Sample & Mass $(\mathbf{g})$ & Diameter $(\mathbf{m m})$ & Height $(\mathbf{m m})$ \\
\hline Steel & 28.165 & 22 & 9.73 \\
\hline Copper & 10.13 & 15.9 & 11.6 \\
\hline
\end{tabular}




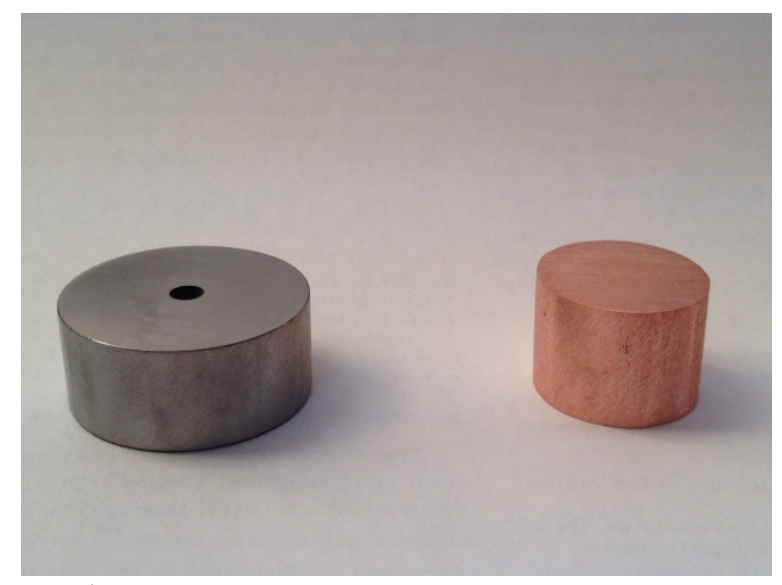

Figure 1. Sample Photographs

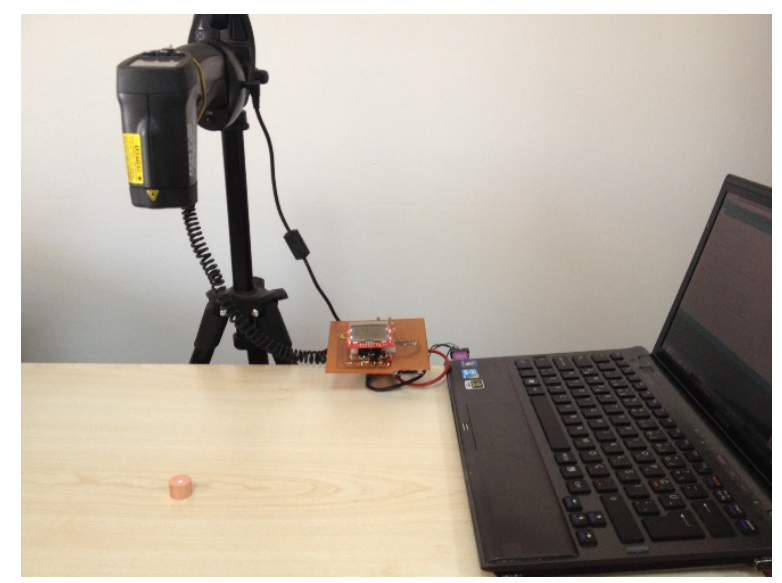

Figure 2. The experimental setup system

\section{Heat transfer model of the experiment system}

The sample whose heat transfer coefficient to be measured is placed on a wood table. Therefore, its surface sample area except its base are surrounded by air which does not flow. The woodthe sample base boundary is taken as an adiabatic boundary in which no heat is gained or lost by the system. Since the heat transfer from the bottom base area of the sample to the wood is ignored, i.e. the bottom base of the sample is taken mathematically as a Neumann boundary. The air temperature is assumed to be constant. Therefore, the system can lose heat due to both natural convection and radiation throughout the surrounding air. It is predicted that most of the heat transfer dynamics from the sample being cooled are governed by convection since the sample temperature is not enough to have a considerable radiation power. The surface temperature measurements taken from different points on the metal and intermetallic samples shows that the temperature of the samples on the surface is almost constant and varies only with respect to time. This indicates that the Biot number of the metal and intermetallic samples are low enough to neglect internal thermal dynamics of the samples, i.e. the Biot number, $\mathrm{Bi}<=$ 0.1 [2]. In this case, the sample temperature can be assumed to be uniform within the whole volume and, therefore, the measurement system can be treated simply as a lumped parameter problem. In heat transfer, some bodies are observed to behave like "Lump" whose interior temperature remains essentially uniform at all time during heat transfer (isothermal or uniform temperature distribution). A lumped thermal circuit is a simple approximation to the heat 
transfer model and the equivalent or the lumped thermal circuit of the system studied in this paper is shown in Figure 3.

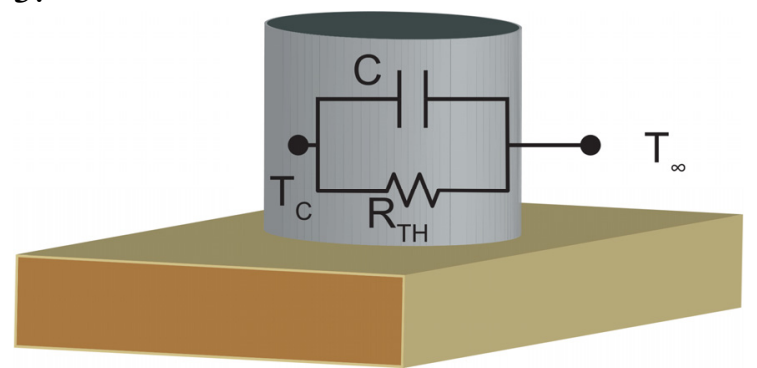

Figure 3. The lumped parameter thermal circuit model of the measurement system during the cooling.

Considering conservation of the energy, assuming the table has a constant temperature, and submitting object physical parameters such as the heat transfer area and the heat transfer coefficient, etc., the differential equation describing sample temperature is given as

$$
\rho_{C} V_{C} c_{C} \frac{d T_{C}}{d t}=-A_{C}\left(k_{S B} \varepsilon T_{C}^{4}+h_{C}\left(T_{C}-T_{\infty}\right)\right)
$$

where $k_{S F}$ is the Stephan-Boltzman constant, $\varepsilon$ is the emissivity, $h_{C}$ is the convection constant of the sample, $A_{C}=\pi r^{2}+2 \pi r \ell$ is the total area of the sample surrounded by the air, $T_{\infty}$ is the ambient temperature, $T_{C}$ is the instantaneous sample temperature, $\rho_{C}$ is the sample mass density, $V_{C}$ is the sample volume, $c_{C}$ is the sample specific heat capacitance.

Since the radiation loss is ignored since the samples are not heated to very high temperatures, (1) turns into

$$
m_{C} c_{C} \frac{d T_{C}}{d t} \cong-A_{C} h_{C}\left(T_{C}-T_{\infty}\right)
$$

where $m_{C}$ is the sample mass.

The convection thermal resistance is given as

$$
R_{T H}=1 /\left(h_{C} A_{C}\right)
$$

(2) turns into

$$
\frac{d\left(T_{C}-T_{\infty}\right)}{d t} \cong-\frac{\left(T_{C}-T_{\infty}\right)}{R_{T H} C}
$$

where $C=m_{C} c_{C}$ is the sample heat capacitance. The solution of (4) is given as

$$
T_{C}(t)=T_{C}\left(t_{0}\right) e^{-\frac{t-t_{0}}{R_{T H} C}}+T_{\infty}=T_{C}\left(t_{0}\right) e^{-\frac{t-t_{0}}{\tau}}+T_{\infty}
$$

where $T_{C}\left(t_{0}\right)$ is the initial temperature at time $t_{0}, T_{\infty}$ is the ambient temperature, $\tau$ is the thermal time constant and is given as

$$
\tau=R_{T H} C=m_{C} c_{C} R_{T H}=m_{C} c_{C} /\left(h_{C} A_{C}\right)
$$

In the next chapter, using the experimental data and curve fitting, the thermal time constant is to be obtained. 


\section{Convection Coefficient Estimation}

\subsection{Experimental Results}

Two experiments are performed to record sample temperatures with respect to time with this experimental setup shown in Figure 2. The sample temperatures for steel and copper are acquired with respect to time as shown in Figure 4 and Figure 5. The infrared thermometer shows that the temperature distribution is uniform on the sample cooling areas. The samples are heated up for a considerable amount time in the oven. The sample is taken out of the oven using a pair of pincers. This results in some heat loss to the pincers and throughout it to the ambiance. As a result of the loss, the sample temperature on the surface becomes less than the interior sample temperature. That's why, if it is waited for a while, the sample temperature increases first due to the fact that the interior sample temperature is higher than the surface temperature and the power flows from inside to outside and the sur. After the thermal balance is reached within the sample (the sample temperature stops increasing), the sample temperature starts decreasing and its profile resembles an exponential curve. The sample temperature keeps falling down to the ambient temperature and that lumped system is applicable. The experiments are performed long enough to obtain a good cooling data. However, the experiment is finished before temperature becomes equal to the ambient temperature. By post-processing the experimental data, the thermal time constants of the samples are to be estimated in the next section.

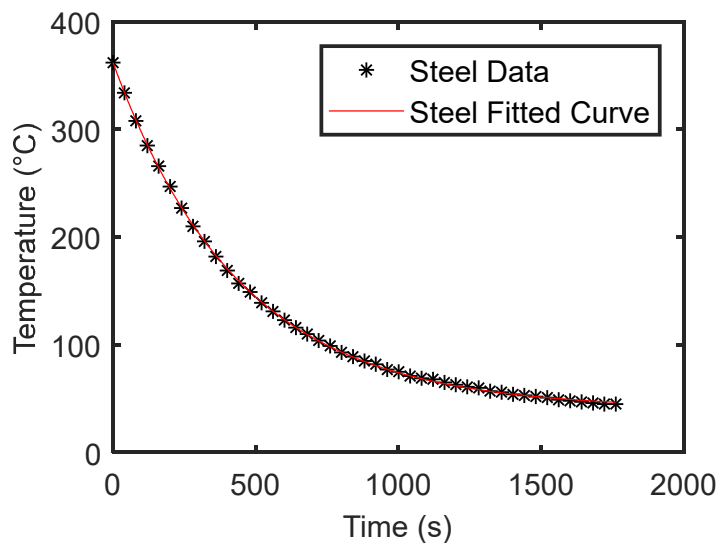

Figure 4. The steel sample temperature and fitted curve versus time

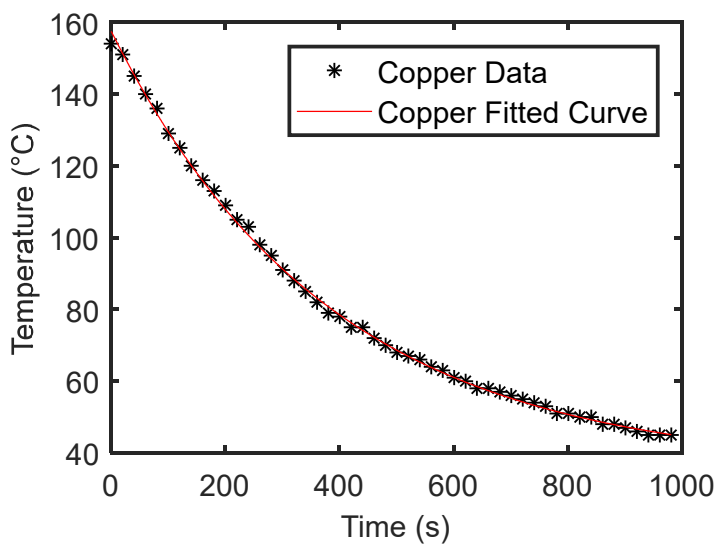

Figure 5. The Copper sample temperature and fitted curve versus time

\subsection{Convection Coefficient Estimation via Curve Fitting}


Matlab is used to curve-fit the experimental data. The curve-fitted functions for the samples are also shown in Figure 4 and Figure 5. The initial time $t_{0}$ is taken to be zero and, therefore, the following curve-fitting function is used:

$$
T=a e^{-b t}+c
$$

The calculated $a, b$ and $c$ coefficients are shown in Table 2. The thermal constants from the experiments are calculated with curve-fitting parameters. The thermal time constant is found as

$$
\tau=1 / b
$$

The convection coefficient of still air can be calculated as

$$
h_{C}=c_{C} m_{C} / \tau A_{C}
$$

The calculated curve-fitting parameters and the specific heat capacity values of copper and steel taken from [2] can be seen in Table 2. Using the values given in Table 1 and Table 2, the following thermal time-constants and the convection coefficients given in Table 3 are calculated. For the case that the air flow speed is zero or for still-air, the convection constant, $h_{C}$, is given equal to $10 \mathrm{~W} /\left(\mathrm{m}^{2} \mathrm{~K}\right)$ in [2]. For the cylindrical samples, we have found it higher than the value given in [2]. Also, this shows that it is dependent on the object dimensions. Typical heat transfer coefficients of air ranges from $h_{C}=10$ to $100 \mathrm{~W} /\left(\mathrm{m}^{2} \mathrm{~K}\right)$ and $15 \%$ uncertainty in convection heat transfer coefficient, $h_{C}$, in most cases is considered normal and expected. Convection coefficient values are obtained as $25.32 \mathrm{~W} /\left(\mathrm{m}^{2} \mathrm{~K}\right)$ and $13.14 \mathrm{~W} /\left(\mathrm{m}^{2} \mathrm{~K}\right)$ for steel and copper, respectively. Considering the $15 \%$ uncertainty and the typical range of the heat transfer coefficients, the calculated values are acceptable.

Table 2. Comparison of the experimental and actual specific heat capacity values.

\begin{tabular}{|c|c|c|}
\hline & Copper & Steel \\
\hline$a$ & 122.0022 & 322.2789 \\
\hline$b$ & 0.0026 & 0.0023 \\
\hline$c$ & 35.7753 & 40.6317 \\
\hline$\tau=1 / b(s n)$ & 384.61 & 434.78 \\
\hline$\left(c_{C}\right)_{\text {databook }}$ & 385 & 450 \\
\hline$C=m_{C} c_{C}$ & 4.4524 & 6.9766 \\
\hline
\end{tabular}

Table 3. Convection coefficient of still air measured for steel and copper samples.

\begin{tabular}{|c|c|c|}
\hline & Copper & Steel \\
\hline$h_{C}=c_{C} m_{C} / \tau A_{C}$ & $13.14 \mathrm{~W} /\left(\mathrm{m}^{2} \mathrm{~K}\right)$ & $25.32 /\left(\mathrm{m}^{2} \mathrm{~K}\right)$ \\
\hline
\end{tabular}

\section{Conclusion}

In this paper, using an infrared thermometer, the sample temperature versus time during cooling is acquired. The analytical solution of the cooling equation is given ignoring the radiation heat loss. Then, using curve-fitting of the experimental data, the unknown parameters of the solution are calculated. The convection coefficient of still air is calculated using the thermal time constant found from the curve-fitting. Two different estimation of the convection coefficient of still air using samples of copper and steel are made. 
In the literature, typical heat transfer coefficients of air are given to ranges from 10 to 100 $\mathrm{W} /\left(\mathrm{m}^{2} \mathrm{~K}\right)$ and $15 \%$ uncertainty in convection heat transfer coefficient is usually acceptable. Convection coefficient values are obtained as $25.32 \mathrm{~W} /\left(\mathrm{m}^{2} \mathrm{~K}\right)$ and $13.14 \mathrm{~W} /\left(\mathrm{m}^{2} \mathrm{~K}\right)$ for steel and copper, respectively. The calculated values stay within the typical range of the heat transfer coefficients given in databooks. This shows the method's applicability. Therefore, universities without more sophisticated measurement systems can use the method given in this paper to estimate the convection coefficient of still air since it is a cheap and easy-to-use method and only requires an infrared thermometer. In this paper, only metallic samples are used in

experiments. For insulator samples, a more sophisticated heat transfers or lumped-parameter thermal circuit model which takes the heat transfer into the wood should be taken into account.

\section{References}

[1] Doebelin, E.O., "System dynamics: modeling and response", Merrill (1972).

[2] Çengel, Y.A., Ghajar, A.J., "Heat and mass transfer : fundamentals \&amp; applications", McGraw-Hill Education, 5 edition (2014).

[3] Vollmer, M., "Newton's law of cooling revisited", Eur. J. Phys. 30 (5) (2009) : 1063 1084.

[4] Hireholi, S., Shashishekhar, K.S., Milton, G.S., "Experimental and theoretical study of heat transfer by natural convection of a heat sink used for cooling of electronic chip", (2013).

[5] Himrane, N., Ameziani, D.E., Bennacer, R., "Effect of the weather conditions on natural convection in storage silo", in 3rd International Symposium on Environmental Friendly Energies and Applications (EFEA) (2014) : 1-6.

[6] Bagnall, K.R., Muzychka, Y.S, Wang, E.N., "Application of the kirchhoff transform to thermal spreading problems with convection boundary conditions", IEEE Trans. Components, Packag. Manuf. Technol. 4 (3) (2014) : 408-420.

[7] Yu, L., Liu, D., "Study of the thermal effectiveness of laminar forced convection of nanofluids for liquid cooling applications", IEEE Trans. Components, Packag. Manuf. Technol. 3 (10) (2013) : 1693-1704.

[8] Farahmand, F., Dawson, F.P., Lavers, J.D., "Temperature rise and free-convection heattransfer coefficient for two-dimensional pot-core inductors and transformers", IEEE Trans. Ind. Appl. 45 (6) (2009) : 2080-2089.

[9] Chang, S.W., "Forced heat convection in a reciprocating duct fitted with 45 degree crossed ribs", Int. J. Therm. Sci., 41 (3) (2002) : 229-240.

[10] Moraga, N.O., Marambio, M.A., Cabrales, R.C., "Geometric multigrid technique for solving heat convection-diffusion and phase change problems", Int. Commun. Heat Mass Transf. 88 (2017) : 108-119.

[11] Wang, C., Qiu, Z., Yang, Y., "Collocation methods for uncertain heat convectiondiffusion problem with interval input parameters", Int. J. Therm. Sci. 107 (2016) : 230236.

[12] Gong, X., Yang, X., Luo, Q., Tang, L., "Effects of convective heat transport in modelling the early evolution of conduits in limestone aquifers", Geothermics 77 (2019) : 383-394.

[13] Castanet, G., Frackowiak, B., Tropea, C., Lemoine, F., "Heat convection within 
evaporating droplets in strong aerodynamic interactions", Int. J. Heat Mass Transf. 54 (15-16) (2011) : 3267-3276.

[14] Natale, M.F., Santillan Marcus, E.A., "The effect of heat convection on drying of porous semi-infinite space with a heat flux condition on the fixed face $\mathrm{x}=0$ ", Appl. Math. Comput. 137 (1) (2003) : 109-129.

[15] Belhocine, A., Wan Omar, W.Z., "Numerical study of heat convective mass transfer in a fully developed laminar flow with constant wall temperature", Case Stud. Therm. Eng. 6 (2015) : 116-127.

[16] (Tim) Shih, T.-M., Thamire, C., Zhang, Y., "Heat convection length for boundary-layer flows", Int. Commun. Heat Mass Transf. 38(4) (2011) : 405-409.

[17] Yener, S. C., Yener, T., Mutlu, R., "A process control method for the electric currentactivated/assisted sintering system based on the container-consumed power and temperature estimation”, J. Therm. Anal. Calorim. 134 (2) (2018) : 1243-1252.

[18] Thellier, F., Monchoux, F., Spagnol, S., Bonnis-Sassi, M., "Measurement of ambient air temperature for evaluation of human heat convective losses", Measurement 42 (1) (2009) : 62-70.

[19] Faraji, M., El Qarnia, H., "Numerical study of free convection dominated melting in an isolated cavity heated by three protruding electronic components", IEEE Trans. Components Packag. Technol. 33 (1) (2010) : 167-177.

[20] Yaacob, Z., Hasan, M.K., "Nonstandard finite difference schemes for natural convection in an inclined porous rectangular cavity", International Conference on Electrical Engineering and Informatics (ICEEI) (2015) : 665-669.

[21] Yang, X., Mao, Z., Wu, Y., Liang, L., Bi, Y., "Numerical simulation on convection heat transfer of pulsating flow in corrugated tube", International Conference on Materials for Renewable Energy \& Environment (2011) : 1882-1884.

[22] Shafiq, F., Ullah, A., Chughtai, I., Hamid, A., Nadeem, M., "CFD study of natural convection heat transfer from an enclosed assembly of vertical cylinders", 14th International Bhurban Conference on Applied Sciences and Technology (IBCAST) (2017) : 519-522.

[23] Cardarelli, F., "Materials handbook : a concise desktop reference”, Springer (2008).

[24] Wujek, S.S., Staats, W.L., Elbel, S.W., Koplow, J.P., Kariya, H.A., Hrnjak, P.S., "Method for determining air side convective heat transfer coefficient using infrared thermography method for determining air side convective heat transfer coefficient using infrared thermography", Purdue e-pubs 2587 (2016).

[25] Conti, R., Gallitto, A.A., Fiordilino, E., "Measurement of the convective heat-transfer coefficient" arXiv:1401.0270v1 (2014).

[26] Garnier, B., Lanzetta, F., Lemasson, P., Virgone, J., "Lecture 5A: Measurements with contact in heat transfer: Principles, implementation and pitfalls", Eurotherm Seminar 94 Advanced Spring School: Thermal measurements \& inverse techniques 5th editionStation Biologique de Roscoff (13-18 June, 2011).

[27] Nakamura, H., "Spatio-temporal measurement of convective heat transfer using infrared thermography", in Heat Transfer - Theoretical Analysis, Experimental Investigations and Industrial Systems InTech (2011). 